\title{
Management of the market business sustainability in the modern business environment
}

\author{
S.Yu. Ilyin*, O.V. Krasnyanskaya ${ }^{2}, O . B$. Gaiman $^{2}, A . A$. Sigankov $^{2}$, and A.V. Bykova ${ }^{2}$ \\ ${ }^{1}$ Financial University under the Government of the Russian Federation, Leningradsky prospect, 51/1, \\ 125993 Moscow, Russian Federation, \\ ${ }^{2}$ MIREA - Russian technological university, Prospekt Vernadskogo, 78, 119454 Moscow, Russia
}

\begin{abstract}
The article is devoted to the author's approach to the formation of management indicators of market sustainability of modern business. The approach is focused on the classical understanding of the market mechanism, which has its own patterns at the current stage of management development, characterized by the high importance of social and ethical marketing, a set of technological costs in the field of production, sales, product promotion and beneficial impact to all community groups. In the course of the study, the resulting and factor indicators were considered: change in income and expenses, direct and indirect ratio of income and profit to process costs for production, sales of products, expenses for corporate social responsibility (strengthening of social well-being as a result of ongoing business activities). These relation-ships between changes in income and expenses were plotted through a combination of their various types (additive, multiplicative, multiple), which help to identify the degree of influence of each factor indicator (element of process costs for marketing activities) on the resulting indicators and take measures to maximize the result and minimize such costs using the computationalconstructive method in its interaction with individual elements of mathematical analysis. The material is useful for entrepreneurs of all spheres and branches of activity, people employed in educational and scientific institutions, specializing in economic and management re-search and disciplines, and their students.
\end{abstract}

\section{Introduction}

The market sector of the economy, in comparison with its public sector, is characterized by a constant and irregular acceleration of socio-economic processes. Therefore, its state largely depends on the stability of the business, primarily, the organizations (legal entities), which are its fundamental link, in contrast to individual entrepreneurs (individuals), who are significantly inferior to them in synergy in the implementation of business transactions. Based on the foregoing, the authors see an urgent need to develop a toolkit, which is a group of indicators that serve as a measure (indicators) for commercial organizations in

\footnotetext{
*Corresponding author: i.sergey777@gmail.com
} 
conducting an objective analysis of their entrepreneurial actions in satisfying customers with the required goods and services. The formation of such indicators should, in turn, be adapted to the current realities in supply and demand and to the current stage of management development, which has its own specifics, manifested in the essential role of innovation in each field of activity, and especially in the field of marketing, where in at present, business and corporate social responsibility processes are inextricably combined with each other.

Information sources were the research works devoted to issues of market stability of business in modern economic conditions. Among the authors are O.I. Averin [1], N.S. Antonov [2], A.S. Belanovskii [3], S.N. Efimushkina [4], A.M. Zhemchugova [5], I. Kurnyshev [6], K.V. Pavlova [7], V.A. Rogova [8],T.M. Rogulenko [9], I.A. Soshko [10], B.N. Khosieva [11], whose ideas contain the prerequisites for the formation of indicators for managing the market stability of a business in the current market conditions.

The purpose of the formation of indicators of market business sustainability management is to recommend entrepreneurs to apply their calculation method for their comprehensive business assessment based on the technological factor of an objective result on the effectiveness and cost of marketing projects. Its achievement is based on solving several problems:

1. Disclosure of the laws of business with the existing market mechanism based on scientific and technological achievements.

2. Drawing up a list of elements of entrepreneurial costs, based on the structure of innovative marketing costs.

3. Consolidation of the elements of process costs for marketing into a single nomenclature of costs and comparison of the result with them into a common economic chain, which forms a relationship between the selected resultant and factor indicators for managing the market stability of a business.

These tasks can be solved with the help of the methods and techniques most suitable for the chosen research topic.

\section{Methods}

The research is based on the calculation-constructive method, which integrates additive, multiplicative, and multiple combination when forming economic relationships between the resulting and factor indicators. This approach ensures the complexity and consistency of the analysis of changes in the result and costs, which serve as assessment criteria for market business sustainability (quality of doing business in modern economic conditions) in combination with elements of mathematical analysis that complement he process of detailing the relationship of the investigated resulting and factor indicators.

The chosen methods to evaluate the indicators of market business sustainability management al-lows entrepreneurs to obtain, in general and in particular, accurate information about the influence of factor indicators on the resulting indicators (for individual technological elements in the field of marketing), which, in turn, affect the result and costs (leading factors of efficiency and competitiveness).

\section{Results}

The formation of management indicators for the market business sustainability is based on the following operation patterns of the modern market:

1. Significant influence of the concept of social and ethical marketing on production and marketing processes. According to the concept, the task of the organization to achieve the 
desired financial benefits is to meet the needs of the market in more efficient ways than those of competitors, while maintaining and strengthening the well-being of customers and society as a whole. This means that in addition to the costs of producing and selling products, the entrepreneurial mission is to focus the attention of manufacturers (sellers) on material and spiritual values simultaneously.

2. Unity of measures to assess production and sales opportunities, develop a marketing strategy and marketing program, implement product, price, distribution policy, generate demand, stimulate product sales, and take care of the full life of the population, including those who have no interest in these products. Only their integrity can provide the desired elasticity of sales of manufactured products.

3. The key role of the technological factor in the production and marketing of products. Without innovative developments, both in the economic and in social spheres of entrepreneurship, doing business does not give a stable volume of sales, as in the period of scientific and technological advances, it is technologies that are the key to optimal productivity of living and materialized labor, quality and competitiveness of products at the national and international levels, which are the main attributes of the modern market environment that predetermine both supply and demand.

Following these patterns as reference, we will phase works on doing business, during which the marketing costs are calculated:

1. Expenses for innovations in the production of products (processing of raw materials, production of materials and semi-finished products, bringing them to finished products, checking its quality and testing its suitability for use).

2. Expenses for innovations in product sales (transportation, promotion, insurance of the received finished product).

3. Expenses on innovation for corporate social responsibility (maintaining and strengthening the well-being of customers and other members of society).

All these marketing costs are subject to comparison with the results of business (income and prof-its from sale) to calculate the effectiveness and cost of marketing projects, as both of them determine the quality of entrepreneurial actions. Accordingly, the fundamental component of business sustainability management indicators should be indicators related to the business performance (formulas (1), (2), (3), (4)):

$$
E f_{b(i)}=\frac{I_{b}}{C_{p r i n}+C_{p s i n}+C_{c s r}},
$$

Where $E f_{\mathrm{b}(\mathrm{i})}$ is business income efficiency;

$I_{\mathrm{b}}$ is business income, rub.;

$C_{\text {prin }}$ is the product release innovation costs, rub.;

$C_{\mathrm{psin}}$ is the product sale innovation costs, rub.;

$C_{\text {csr }}$ is the corporate social responsibility innovation costs, rub.;

$$
E f_{b(i)}=\frac{P_{b}}{C_{p r i n}+C_{p s i n}+C_{c s r}},
$$

Where $E f_{\mathrm{b}(\mathrm{p})}$ is business profit efficiency;

$P_{\mathrm{b}}$ is business profit, rub.;

$C_{\text {prin }}$ is the product release innovation costs, rub.;

$C_{\mathrm{psin}}$ is the product sale innovation costs, rub.;

$C_{\text {csr }}$ is the corporate social responsibility innovation costs, rub.;

$$
E f_{\text {indb }(i)}=\frac{c_{p r i n}+C_{p s i n}+C_{c s r}}{I_{b}},
$$


Where $E f_{\text {indb(i) }}$ is indirect business income efficiency;

$C_{\text {prin }}$ is the product release innovation costs, rub.;

$C_{\text {psin }}$ is the product sale innovation costs, rub.;

$C_{\text {csr }}$ is the corporate social responsibility innovation costs, rub.;

$I_{\mathrm{b}}$ is business income, rub.;

$$
E f_{\text {indb }(p)}=\frac{c_{\text {prin }}+c_{p s i n}+c_{c s r}}{P_{b}},
$$

Where $E f_{\text {indb(p) }}$ is indirect business profit efficiency;

$C_{\text {prin }}$ is the product release innovation costs, rub.;

$C_{\mathrm{psin}}$ is the product sale innovation costs, rub.;

$C_{\text {crr }}$ is the corporate social responsibility innovation costs, rub.;

$P_{\mathrm{b}}$ is business profit, rub.

Next, we will form indicators of market business sustainability management, focusing on their essence, which means maximizing the result and minimizing costs in a qualitative way (formulas (5), (6), (7), (8)):

$$
\Delta I_{b}=\left[\frac{I_{b 1}}{C_{p r i n 1}+C_{p \sin 1}+C_{c s r 1}}-\frac{I_{b 0}}{C_{p r i n 0}+C_{p s i n 0}+C_{c s r 0}}\right] *\left(C_{p r i n 1}+C_{p \sin 1}+C_{c s r 1}\right),
$$

Where $\Delta I_{\mathrm{b}}$ is the change in income due to changes in the direct business income efficiency, rub.; $I_{\mathrm{b} 1}$ is business income in the reporting period, rub.;

$C_{\text {prin } 1}$ is the product release innovation costs in the reporting period, rub.;

$C_{\mathrm{psin} 1}$ is the product sale innovation costs in the reporting period, rub.;

$C_{\text {csrl } 1}$ is the corporate social responsibility innovation costs in the reporting period, rub.;

$I_{\mathrm{b} 0}$ is business income in the reference period, rub.;

$C_{\text {prino }}$ is the product release innovation costs in the reference period, rub.;

$C_{\mathrm{psin} 0}$ is the product sale innovation costs in the reference period, rub.;

$C_{\text {csro }}$ is the corporate social responsibility innovation costs in the reference period, rub.;

$$
\Delta P_{b}=\left[\frac{P_{b 1}}{C_{p r i n 1}+C_{p s i n 1}+C_{c s r 1}}-\frac{P_{b 0}}{C_{p r i n 0}+C_{p s i n 0}+C_{c s r 0}}\right] *\left(C_{p r i n 1}+C_{p \sin 1}+C_{c s r 1}\right),
$$

Where $\Delta P_{\mathrm{b}}$ is the change in profit due to changes in the direct business profit efficiency, rub.;

$P_{\mathrm{b} 1}$ is business profit in the reporting period, rub.;

$C_{\text {prin }}$ is the product release innovation costs in the reporting period, rub.;

$C_{\mathrm{psin} 1}$ is the product sale innovation costs in the reporting period, rub.;

$C_{\text {csrl }}$ is the corporate social responsibility innovation costs in the reporting period, rub.;

$P_{\mathrm{b} 0}$ is business profit in the reference period, rub.;

$C_{\text {prino }}$ is the product release innovation costs in the reference period, rub.;

$C_{\mathrm{psin} 0}$ is the product sale innovation costs in the reference period, rub.;

$C_{\text {csro }}$ is the corporate social responsibility innovation costs in the reference period, rub.;

$$
\Delta P C_{b / i}=\left[\frac{C_{p r i n 1}+C_{p s i n 1}+C_{c s r 1}}{I_{b 1}}-\frac{c_{p r i n 0}+C_{p s i n 0}+C_{c s r 0}}{I_{b 0}}\right] * I_{b 1}
$$

Where $\triangle P C_{\mathrm{b} / \mathrm{i}}$ is the change in process costs due to changes in the indirect business income efficiency, rub.;

$C_{\text {prin } 1}$ is the product release innovation costs in the reporting period, rub.;

$C_{\mathrm{psin} 1}$ is the product sale innovation costs in the reporting period, rub.;

$C_{\text {csrl }}$ is the corporate social responsibility innovation costs in the reporting period, rub.;

$I_{\mathrm{b} 1}$ is business income in the reporting period, rub.;

$C_{\text {prino }}$ is the product release innovation costs in the reference period, rub.; 
$C_{\mathrm{psin} 0}$ is the product sale innovation costs in the reference period, rub.;

$C_{\mathrm{csr} 0}$ is the corporate social responsibility innovation costs in the reference period, rub.;

$I_{\mathrm{b} 0}$ is business income in the reference period, rub.;

$$
\Delta P C_{b / p}=\left[\frac{c_{p r i n 1}+c_{p s i n 1}+c_{c s r 1}}{P_{b 1}}-\frac{c_{p r i n o}+c_{p s i n o}+c_{c s r 0}}{P_{b 0}}\right] * P_{b 1},
$$

Where $\triangle P C \mathrm{~b} / \mathrm{p}$ is the change in process costs due to changes in the indirect business profit efficiency, rub.;

$C_{\text {prin } 1}$ is the product release innovation costs in the reporting period, rub.;

$C_{\mathrm{psin} 1}$ is the product sale innovation costs in the reporting period, rub.;

$C_{\text {csrl }}$ is the corporate social responsibility innovation costs in the reporting period, rub.;

$P_{\mathrm{b} 1}$ is business profit in the reporting period, rub.;

$C_{\text {prino }}$ is the product release innovation costs in the reference period, rub.;

$C_{\mathrm{psin} 0}$ is the product sale innovation costs in the reference period, rub.;

$C_{\text {csro }}$ is the corporate social responsibility innovation costs in the reference period, rub.;

$P_{\mathrm{b} 0}$ is business profit in the reference period, rub.

The formed indicators fully correspond to the traditional understanding of assessing the degree of influence of qualitative parameters on the result and costs, as the change in income, profit, and costs depends on both direct and indirect indicators of business efficiency and at the same time consists of elements adapted to the newest social formation built on the key role of the technological factor in the marketing processes.

\section{Discussion}

Table 1, 2 presents the interpretation of the formed indicators of market business sustainability management.

Table 1. Interpretation of market business sustainability management indicators by income

\begin{tabular}{|l|l|}
\hline \multicolumn{1}{|c|}{ Indicator } & \multicolumn{1}{|c|}{ Content } \\
\hline $\begin{array}{l}\text { The change in income due to changes in the } \\
\text { direct business income efficiency }\end{array}$ & $\begin{array}{l}\text { An increase/decrease in income due to an } \\
\text { increase/decrease in the result (income) in } \\
\text { relation to the total costs of marketing } \\
\text { technologies, including the costs of innovations } \\
\text { in the production, sales of products, and } \\
\text { corporate social responsibility }\end{array}$ \\
\hline $\begin{array}{l}\text { The change in costs due to changes in the } \\
\text { indirect business income efficiency }\end{array}$ & $\begin{array}{l}\text { Saving (cost overrun) of funds by } \\
\text { increasing/reducing the cost of marketing } \\
\text { technologies, including the cost of innovation } \\
\text { in the production, sales of products, corporate } \\
\text { social responsibility, in relation to the result } \\
\text { (income) }\end{array}$ \\
\hline
\end{tabular}


Table 2. Interpretation of market business sustainability management indicators by profit

\begin{tabular}{|l|l|}
\hline \multicolumn{1}{|c|}{ Indicator } & \multicolumn{1}{|c|}{ Content } \\
\hline $\begin{array}{l}\text { The change in profit due to changes in } \\
\text { the direct business profit efficiency }\end{array}$ & $\begin{array}{l}\text { An increase/decrease in profit due to an } \\
\text { increase/decrease in the result (profit) in } \\
\text { relation to the total costs of marketing } \\
\text { technologies, including the costs of } \\
\text { innovations in the production, sales of } \\
\text { products, and corporate social } \\
\text { responsibility ing }\end{array}$ \\
\hline $\begin{array}{l}\text { The change in costs due to changes in } \\
\text { the indirect business profit efficiency }\end{array}$ & $\begin{array}{l}\text { Saving (cost overrun) of funds by } \\
\text { increasing/reducing the cost of marketing } \\
\text { technologies, including the cost of } \\
\text { development, implementation, and } \\
\text { application of innovations, in relation to } \\
\text { the result (profit) }\end{array}$ \\
\hline
\end{tabular}

They show the following advantages of the indicators of business market sustainability management proposed by the authors:

1. Compliance with the requirements of the modern market operating based on innovative entrepreneurial actions, consisting of a set of marketing processes necessary to achieve financial benefits.

2. The presence of elements that entirely and comprehensively reflect the requirements for the good marketing activity.

3. A potential for making timely decisions to improve the results and costs of technologies for the implementation of marketing projects.

Using these advantages, entrepreneurs can objectively calculate the level of business efficiency and take all the necessary measures to maximize income and profits and minimize the relevant costs related to the use of marketing technologies.

\section{Conclusion}

The author's indicators of market business sustainability management are adapted to modern economic conditions, as they correspond to the realities of the current management evolution stage, at which the priority of science in the use of human and investment resources is undeniable. For entrepreneurs, they will serve as a toolkit for a comprehensive and systematic assessment of the quality of doing business and implementing innovative procedures that optimize marketing efforts.

These indicators include the entire list of process costs in marketing, consisting of procedures for production, sales of products, corporate social responsibility, necessary to obtain the required profit margin and profitability in the course of business.

Thus, the authors have achieved the set objective and completed the tasks by meeting all requirements for the formation of market business sustainability management indicators related to the mandatory consideration of the primacy of the technological factor in the successful implementation of marketing efforts and optimization of the result and costs of marketing projects. 


\section{References}

1. O.I. Averina, Business performance analysis: evaluation criteria, International accounting, 41(287), 46 (2013)

2. N.S. Antonova, Sales management, 2, $136(2016)$

3. A.S. Belanovskii, Sales management, 1, 34 (2017)

4. S.N. Efimushkin, A.S. Krasnikova, Creative economy, 12(96), 63 (2014)

5. A.M. Zhemchugov, M.K. Zhemchugov, Management today, 3, 196 (2017)

6. I. Kurnysheva, S. Lykov, A. Idrisov, Competitiveness and problems of structural moderni-zation. Ekonomist, 9, 39 (2008)

7. K.V. Pavlov, S.N. Rastvortseva, Management and control of socio-economic efficiency: problems and tasks, National interests: priorities and security, 4, 4(25), 28 (2008)

8. V.A. Rogova, Russian technological journal, 4, 105 (2018)

9. T.M. Rogulenko, D.A. Pozov, University Bulletin, 4, 130 (2015)

10. I.A. Soshko, Bulletin of Chu-vash University, 4, 90 (2014)

11. B.N. Khosiev, G.Ia. Ostaev, Z.T. Kokoeva, Accounting in agriculture, 5, 39 (2018) 